\title{
Surficial Failure of Expansive Soil Cutting Slope and Its Flexible Support Treatment Technology
}

\author{
Jie Xiao, ${ }^{1,2}$ He-ping Yang, ${ }^{1}$ Jun-hui Zhang $\mathbb{D}^{1,2}$ and Xian-yuan Tang ${ }^{1}$ \\ ${ }^{1}$ Engineering Research Center of Catastrophic Prophylaxis and Treatment of Road and Traffic Safety of Ministry of Education, \\ Changsha University of Science and Technology, Changsha 410114, China \\ ${ }^{2}$ National Engineering Laboratory of Highway Maintenance Technology, Changsha University of Science and Technology, \\ Changsha 410114, China \\ Correspondence should be addressed to Jun-hui Zhang; zjhseu@163.com
}

Received 31 July 2017; Revised 17 November 2017; Accepted 13 December 2017; Published 11 February 2018

Academic Editor: Claudio Tamagnini

Copyright ( 2018 Jie Xiao et al. This is an open access article distributed under the Creative Commons Attribution License, which permits unrestricted use, distribution, and reproduction in any medium, provided the original work is properly cited.

\begin{abstract}
The surficial failure of most expansive soil cutting slopes, subjected to the repeated wet-dry cycles, often occurs during or after rainfall following a long drought. The reason for this, however, is still unclear. Therefore, the laboratory tests were conducted to gain the saturated drained shear strength of the natural Nanning expansive soil considering the combined effects of swelling with loading and wet-dry cycles. The findings indicate that the envelope of shear strength, which significantly drops close or equal to zero, can be well fitted by the generalized power function. At the same time, the effect of shear strength parameters on the stability of the expansive soil cutting slope was investigated. The reasons for the shear strength attenuation of the natural expansive soil and the surficial failure of the expansive soil cutting slopes were analyzed. It is evident that the effective cohesion being small is a vital factor influencing the occurrence of surficial failure of an expansion soil slope. Moreover, an effective flexible support treatment measure was provided.
\end{abstract}

\section{Introduction}

Expansive soils, which are regarded as a problem soil, are typically encountered around the world. The total distribution areas of expansive soil are more than one hundred thousand square kilometers in China [1]. These soils have three typical properties (i.e., significant swelling and shrinkage, fissures, and overconsolidation) due to hydrophilic minerals such as montmorillonite. Their strengths are particularly sensitive to changes in the surrounding environment.

The failure of expansive soil slopes, especially surficial failure, is one of the most serious geological disasters that frequently occurs during the construction of highways, railways, and hydraulic engineering projects in expansive soil areas in China [1]. Figure 1 shows a surficial failure of an expansive soil cutting slope in Nanning-Baise expressway in Guangxi Zhuang Autonomous Region, China. Numerous researchers have studied the depth of the surficial failure of expansive soil slopes by field investigations. Liao [1] concluded that the surficial failure depths of most expansive soil slopes were in the range of 1.0 to $3.0 \mathrm{~m}$, which was close to the development depth of fissures [2]. Wang et al. [3] reported that the sliding depth generally ranged from 1.0 to $2.5 \mathrm{~m}$, and the reason for the surficial failure of expansive soil slopes may be a drastic reduction in the strength of slope surface soil. It results from the occurrence of swellingshrinkage cracking and fissures due to the repeated wetdry cycles. The Yangtze River Scientific Research Institute and Wuhan University found that the atmosphere influences the depth of the slope at a "critical depth" of approximately $1.5 \mathrm{~m}$ by analyzing the measurement results of the suction matrix in expansive soil slopes in the field [4].

For an engineering project, the shear strength of expansive soils is required to address the stability of expansive soil slopes. A review of the technical literatures revealed that the investigation of shear strength behavior of expansive soils was limited, especially, with respect to the effect of 


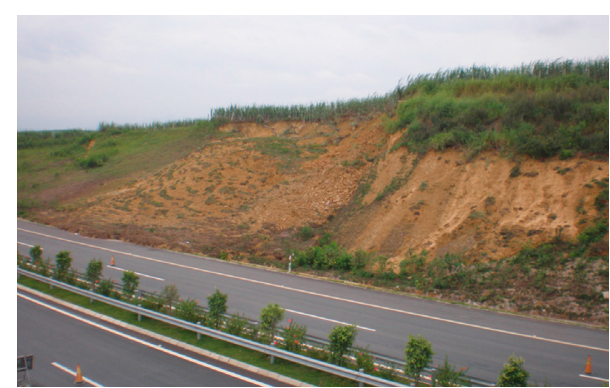

Figure 1: Photo of surficial failure of an expansive soil cut slope.

swelling. Dinesh and Chandra [5] reported that the shear strength of the saturated Indian black cotton soil is reduced with increasing moisture content. Similar research was conducted by Sun et al. [6] and Elkady and Abbas [7]. Direct shear tests on Egyptian expansive clays by Sherif et al. [8] indicated that the undrained shear strength prior to swelling is 3 to 5.5 times higher than that after swelling. Darrag [9] attributed the reduction in the undrained shear strength to the cohesive reduction in swelling, rather than to the friction angle. Al-Mhaidib and Al-Shamrani [10] reported that the shear strength of the expansive shale and bentonite, obtained from triaxial testing, decreased by $70 \%$ to $90 \%$ because of a full swelling. Wong [11] investigated the effect of both swelling and confining stress on the shear strength of an expansive shale, and found that the shear strength of the tested shale decreased with increasing swelling. Zhang et al. [12] discussed the impact of wet-dry cycles with loading on the expansive soil strength but did not give specific values for shear strength parameters. Other researchers [13-15] evaluated the shear strength envelope of expansive soils and concluded that the relationship between the effective normal stress and shear strength for expansive clays may be linear or bilinear, which depends on the initial void ratio of the tested samples.

The effective normal stress on the failure plane is very small and commonly varies from approximately 10 to $30 \mathrm{kPa}$ due to the surficial nature of slope failures. This stress is significantly lower than the actual range of stresses at which specimens are usually tested for investigating the slope stability of expansive soils. Therefore, the results of slope stability by applying the shear strength parameters obtained by universal tests could not be explained nationally since the saturated peak drained shear strength parameters of the expansive soil under wet-dry cycles, or as the residual drained shear strength parameters $[16,17]$ were often not low. For example, a Nanyang expansive soil cutting slope had an average slope ratio of $1: 2(\mathrm{~V}: \mathrm{H})$, and the calculated factor of safety was 2.7 using the universal shear strength parameters; however, the surficial failure of the slope occurred, and even though the slope was flattened to $1: 4$, a sliding failure still happened [1]. To explain this phenomenon, some researchers $[1,18]$ even proposed that the friction angle and cohesion for calculating the slope stability should be $1 / 7$ and $1 / 14$, respectively, of those achieved by experimental results, but these selected strength parameters are irrational due to lack of theory basis.
In summary, little attention has been focused on the shear strength of natural expansive soils influenced by swelling (low stresses) and wet-dry cycles. Therefore, the present paper highlighted the combined effect of swelling with loading and wet-dry cycles on the saturated drained shear strength of natural expansive soils. The effect of shear strength parameters on the stability of expansive soil cutting slope was discussed. The reasons for the shear strength attenuation of natural expansive soils and the surficial failure of expansive soil cutting slopes were analyzed. Finally, an effective and flexible support treatment measure was provided.

\section{Saturated Drained Shear Strength Behavior of Natural Expansive Soils}

2.1. Testing Soils. The expansive soil used in this study was taken from a cutting slope at depths ranging from 2 to $3 \mathrm{~m}$ below the ground surface of the Nanning outer ring expressway in the middle of Guangxi Zhuang Autonomous Region, China. The block samples for natural samples were wrapped with a plastic membrane and waxed cloth to prevent moisture loss (ASTM D4220) [19].

Laboratory tests revealed that the soil has an average natural moisture content of $20.3 \%$ and an average natural density of $2.075 \mathrm{mg} / \mathrm{m}^{3}$. The specific gravity, Gs, of the soil is 2.70. The particle-size distribution indicated that the soil consists of $0.3 \%$ sand, $56.1 \%$ silt, and $43.6 \%$ clay. Therefore, this soil could be classified as a silty clay. The liquid limit (LL) and the plasticity index (PI) are $46.0 \%$ and $22.3 \%$, respectively. The results of the X-ray diffraction test indicated that the predominant clay mineral in the soil is an illitesmectite (58\%) mixed layer. The free swelling rate (FSR) is $62 \%$ obtained by free swell tests (T 0124-1993) performed according to Test Methods of Soils for Highway Engineering (JTG E40-2007) in China. The specific surface area (SSA) is $105.53 \mathrm{~m}^{2} / \mathrm{g}$. The other characteristics of soils are seen in Table 1. According to the Specification for the Design of Highway Subgrades (JTG D30-2004), the potential of the expansive soil could be classified as medium.

2.2. Preparation of Specimens. For the tested natural specimens, suitable sizes of soil blocks were first cut from the block samples and were then trimmed into appropriate dimensions for the saturated drained direct shear tests. The specimens were circular in shape with an inner diameter of $61.8 \mathrm{~mm}$ and a thickness of $20 \mathrm{~mm}$. A sharp-edged cutting tool with the same dimensions for both inner diameter and thickness was used for the trimming. All the cutting and trimming work was conducted in a humidity-controlled room. The differences in dry density and moisture content did not exceed $0.04 \mathrm{~g} / \mathrm{cm}^{3}$ and $1 \%$ for various soil specimens, respectively.

2.3. Wet-Dry Cycle Methods with Loading. In a steel water tank, a properly sized filter was placed on a porous stone under a soil specimen, on which another filter under a porous stone was placed. Since the influence depth effected by 
TABLE 1: Characteristic index of expansive soil.

\begin{tabular}{|c|c|c|c|c|c|c|c|c|}
\hline \multicolumn{4}{|c|}{ Proportion of different particle size $(\mathrm{mm}) / \%$} & Montmorillonite content/\% & \multicolumn{4}{|c|}{$\begin{array}{c}\text { Relative content of clay } \\
\text { minerals } / \%\end{array}$} \\
\hline$>0.075$ & $0.075-0.005$ & $<0.005$ & $<0.002$ & & $I / S$ & $I$ & $K$ & $C$ \\
\hline 0.30 & 56.14 & 43.56 & 42.29 & 11.78 & 58 & 11 & 20 & 11 \\
\hline
\end{tabular}

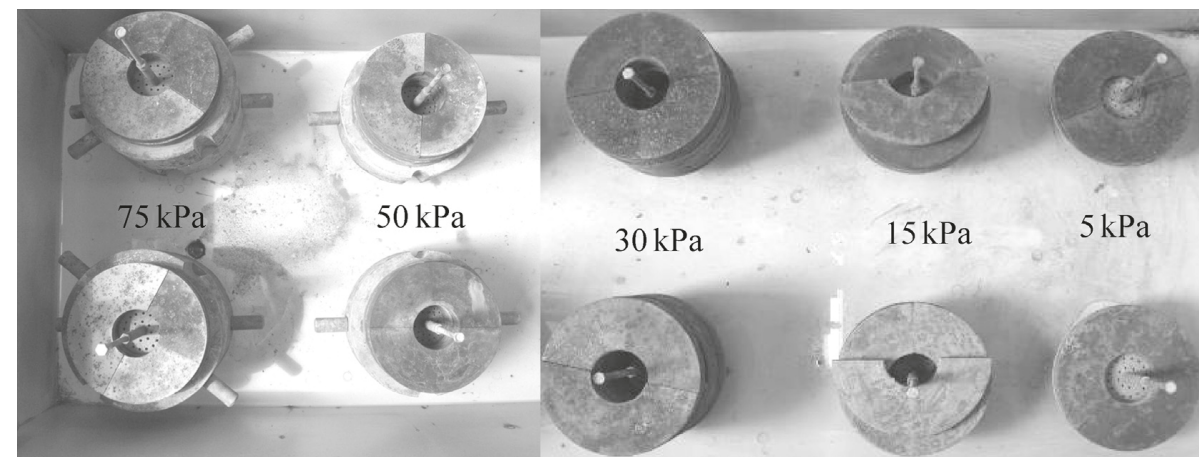

FIGURE 2: Wet-dry cycle saturation with loading.

atmospheric wet-dry cycles is generally shallow, only fivelevel low stress was applied directly by a given loading, as shown in Figure 2. The other samples were saturated by vacuum saturation method. The vacuum pressure (i.e., $-101.325 \mathrm{kPa}$ ) was maintained for $24 \mathrm{~h}$, during which specimen swelling was not permitted. After that, distilled water was slowly added to immerse the specimens to within approximately $1 \mathrm{~cm}$ of the top of the soil specimen for $72 \mathrm{~h}$. Using this saturation technique, saturation degrees of specimens can be achieved more than $98.5 \%$. The saturated specimens were dried at $40^{\circ} \mathrm{C}$ in a hot-air circulator oven for $24 \mathrm{~h}$. The loading was not taken into account in the drying process. Finally, the wet-dry cycle was completed. These cycles were repeated until the prescribed number of cycles was achieved.

2.4. Direct Shear Test. The direct shear apparatus used in this study was manufactured by Nanjing Soil Instrument Factory Technology Co., Ltd. The shear testing procedure follows T 0140-1993 in JTG E40-2007 Test method of soils for highway engineering, which is similar to ASTM D3080 Standard Test Method for Direct Shear Test of Soils under Consolidated Drained Conditions [20]. A prescribed normal load was applied on the saturated specimen until a vertical deformation not exceeding $0.005 \mathrm{~mm} / \mathrm{h}$ occurred, making the specimen completely consolidated. The shearing rate of $0.02 \mathrm{~mm} / \mathrm{min}$ was selected to shear the soil specimen until the horizontal displacement reached $6 \mathrm{~mm}$ in drained conditions.

To reflect the effect of the low normal stress on the drained shear strength, eight normal stresses of 5, 15, 30, 50, $75,100,200$, and $300 \mathrm{kPa}$ were applied. For the universal direct shear tests, the minimum normal stress was $50 \mathrm{kPa}$ applied through a lever loading yoke. Therefore, the three low normal stresses of 5,15 , and $30 \mathrm{kPa}$ were directly applied through equivalent dead weights.

\subsection{Test Results and Analysis}

2.5.1. Shear Behavior of Saturated Natural Expansive Soil Specimens. Figure 3 shows the relationships between shear stress and horizontal displacement at different vertical stress for wet-dry cycles with loading (i.e., 0,2 , 4, and 8 wet-dry cycles).

Except that two stress-displacement curves at vertical stress of $300 \mathrm{kPa}$ at 0 and 2 wet-dry cycles have no peak, the others show a peak. For the two stress-displacement curves having no peak, the maximum shear strength determined is the stress corresponding to the horizontal displacement of $6 \mathrm{~mm}$. In general, the horizontal displacement corresponding to the peak value increases with the increase in vertical stress for different wet-dry cycles. As expected, the maximum shear stress decreases with an increase in wet-dry cycles. The saturation degrees of specimens after shear stageis slightly greater than that before shear, which is similar to the results achieved by Zhan and $\mathrm{Ng}$ [21].

2.5.2. Shear Strength Characteristic of Natural Expansive Soil. Currently, different strength functions have been proposed to describe the nonlinear strength characteristics for soils, such as the bilinear function [22], trilinear function [23], simple power function [24-27], and generalized power function [28]. The generalized power function presented by Baker [28] was utilized to fit the measured data in this study as follows:

$$
\tau=S_{\mathrm{NL}}(\sigma \mid A, n, T) \equiv P_{a} A\left(\frac{\sigma}{P_{a}}+T\right)^{n},
$$

where $\tau$ is the shear strength; $P_{a}$ is the atmospheric pressure; $\{A, n, T\}$ are nonlinear strength parameters; and $S_{\mathrm{NL}}(\sigma \mid A, n, T)$ is the nonlinear strength function. This function has similar features to the Hoek-Brown nonlinear strength criterion for rock mass associated with a Mohr envelope. 


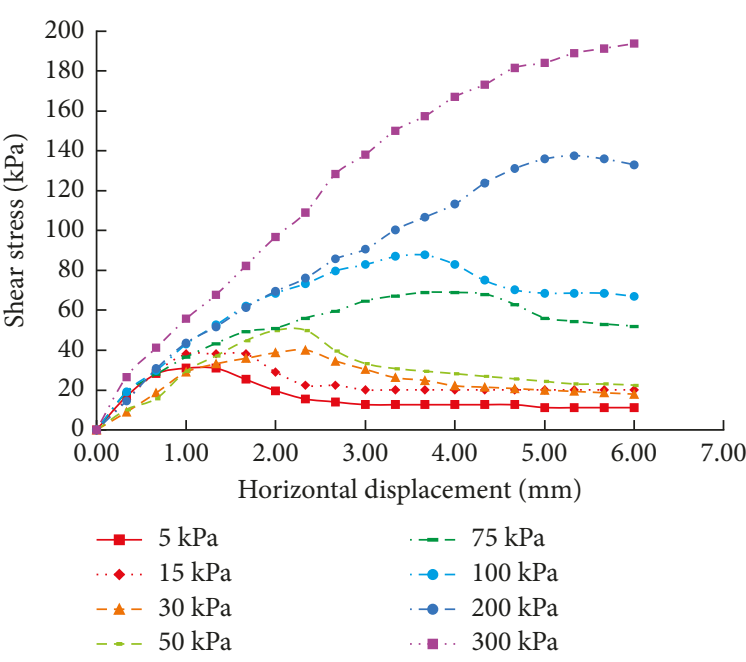

(a)

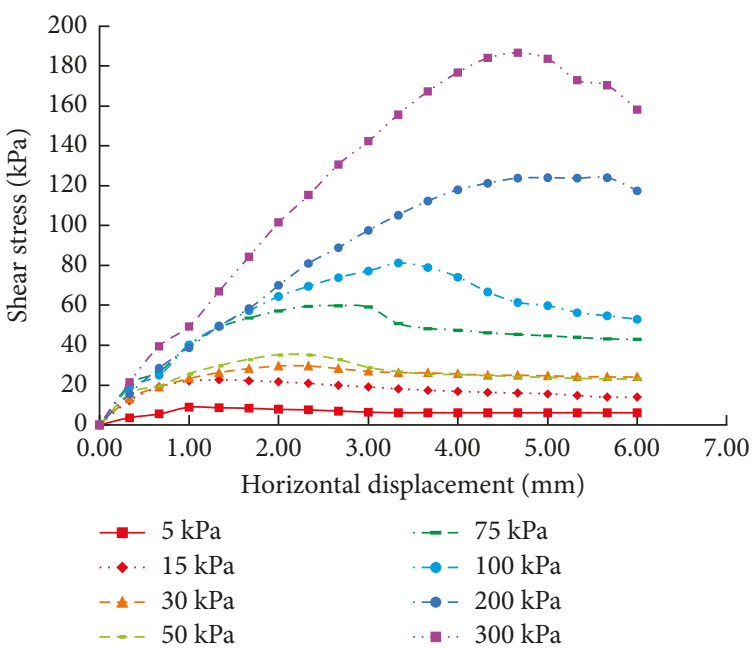

(c)

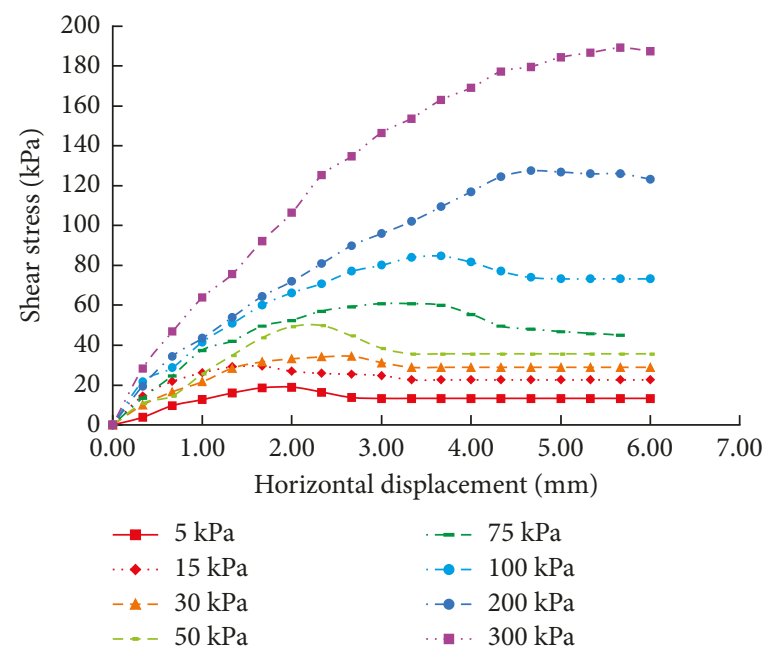

(b)

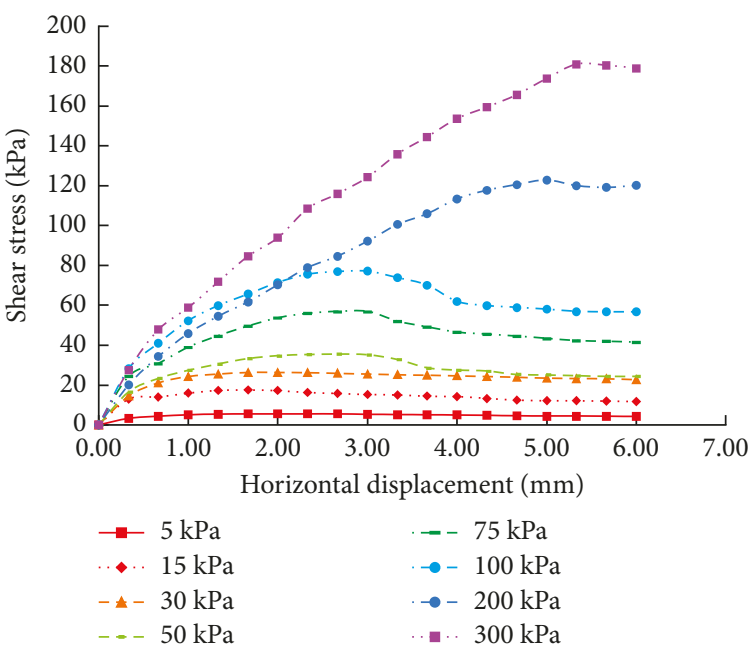

(d)

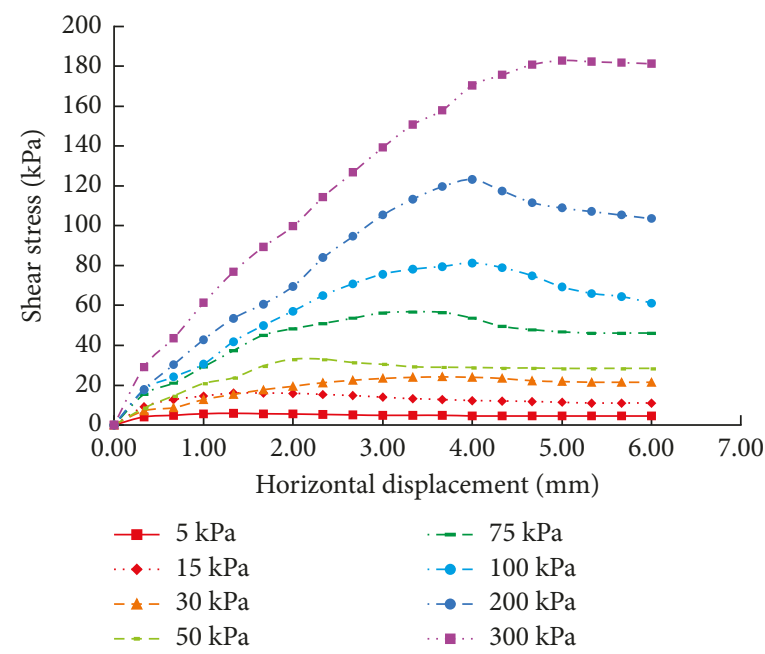

(e)

Figure 3: Results of saturated drained direct shear tests on natural specimens subjected to different wet-dry cycles. (a) Zero wet-dry cycle. (b) Two wet-dry cycles. (c) Four wet-dry cycle. (d) Six wet-dry cycles. (e) Eight wet-dry cycles. 


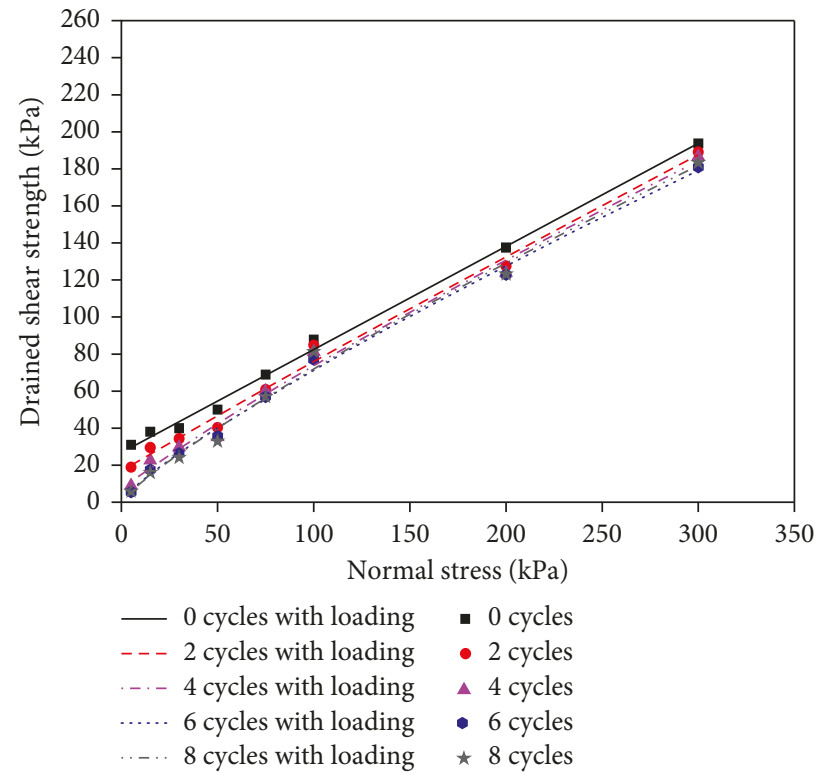

Figure 4: Shear strength variations under wet-dry cycles with loading.

TABLE 2: Shear strength parameters of natural expansive soils under wet-dry cycles with loading.

\begin{tabular}{|c|c|c|c|c|c|c|c|c|}
\hline \multirow[t]{2}{*}{ Number of wet-dry cycles } & \multicolumn{4}{|c|}{ Nonlinear fitting parameters } & \multirow[t]{2}{*}{ The intercept of nonlinear fitting curve $(\mathrm{kPa})$} & \multicolumn{3}{|c|}{$\begin{array}{c}\text { Mohr strength } \\
\text { parameters } \\
(75-300 \mathrm{kPa})\end{array}$} \\
\hline & $A$ & $T$ & $n$ & Adj. $R^{2}$ & & $c^{\prime}(\mathrm{kPa})$ & $\varphi^{\prime}\left({ }^{\circ}\right)$ & $R^{2}$ \\
\hline 0 & 0.5665 & 0.4617 & 0.9889 & 0.9956 & 26.7 & 30.4 & 28.5 & 0.997 \\
\hline 2 & 0.6111 & 0.2535 & 0.9495 & 0.9906 & 16.8 & 23.7 & 28.6 & 0.986 \\
\hline 4 & 0.6900 & 0.0724 & 0.8731 & 0.9898 & 7.1 & 21.6 & 28.4 & 0.988 \\
\hline 6 & 0.7074 & 0.0094 & 0.8417 & 0.9953 & 1.4 & 19.3 & 28.1 & 0.994 \\
\hline 8 & 0.7176 & 0.0000 & 0.8444 & 0.9904 & 0.0 & 20.8 & 28.2 & 0.985 \\
\hline
\end{tabular}

Therefore, it is convenient to analyze the slope stability using the limit equilibrium method. Additionally, the parameters $\{A, n, T\}$ have clear physical meanings, which control the magnitude of the shear strength, the location of the envelope on the $\sigma$ axis, and the curvature of the envelope, respectively.

From (1), the tangential friction angle, $\varphi_{t}$, is determined as follows:

$$
\tan \left[\phi_{t}(\sigma \mid A, n, T)\right] \equiv \frac{d S_{\mathrm{NL}}(\sigma \mid A, n, T)}{d \sigma}=\frac{A n}{\left(\sigma / P_{a}+T\right)^{(1-n)}}
$$

According to (1) and (2), the tangential cohesion intercepts, $c_{t}$, can be determined as follows:

$$
\begin{array}{rl}
c_{t}=P_{a} & A\left(\frac{\sigma}{P_{a}}+T\right)^{n}-\sigma \\
& \times \frac{A n}{\left(\sigma / P_{a}+T\right)^{(1-n)}}=\frac{A\left[(1-n) \sigma+P_{a} T\right]}{\left(\sigma / P_{a}+T\right)^{(1-n)}} .
\end{array}
$$

Figure 4 shows the shear strength of natural specimens subjected to different wet-dry cycles with loading obtained by the results of Figure 3. Table 2 lists the fitting parameters and intercept of the nonlinear fitting curve. For comparison, it also presents the effective cohesion $c^{\prime}$ and effective friction angle $\varphi^{\prime}$ determined by universal high testing normal stress ranges of $75-300 \mathrm{kPa}$. It can be seen from Figure 4 that the shear strength envelope curve is well fitted by the generalized power function mentioned above. The universal saturated drained shear strength becomes fundamentally stable when subjected to four wet-dry cycles, and the effective cohesion and friction angle are approximately $20.0 \mathrm{kPa}$ and $28.0^{\circ}$, respectively. However, it is clear that the intercept at low normal stresses is not stable when subjected to four wet-dry cycles. It gradually decreases from $26.7 \mathrm{kPa}$ to $0 \mathrm{kPa}$ when the numbers of wet-dry cycles increase from 0 to 8 . This indicates that the effect of wet-dry cycles with loading on the saturated drained shear strength of the natural expansive soil at low normal stresses is more significant than that at high stresses. Day [29] suggested that the disproportional swelling of the compacted clay at low effective stresses was the reason for the nonlinear shear strength curve. However, for natural 


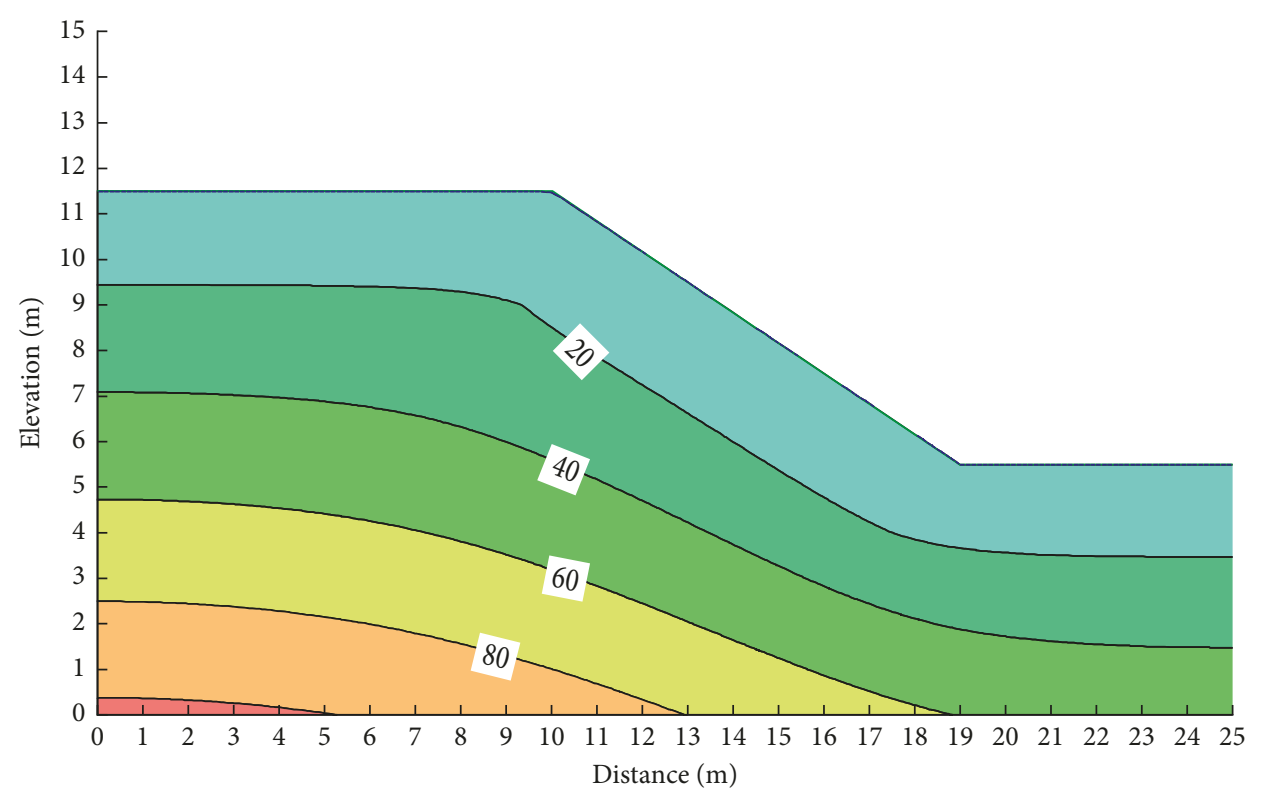

Figure 5: Slope calculation model.

expansive soils, the effect of wet-dry cycles with loading should be also taken into account.

\subsubsection{Discussion on Shear Strength Attenuation of Natural} Expansive Soil. The increase in water content and water film thickness of clay particles in soils will decrease the strength of soils. Overburden pressures significantly influence the amount of water absorbed by the soils, and hence smaller overburden pressures lead to higher soil water absorption capacities. Therefore, it is evident that the water film between the clay particles subjected to lower overburden pressures will be thicker and the dry densities will be lower. When the soil absorbs water in dry conditions, most of the gases in soils could be discharged in the form of bubbles. This process may affect the action on the soil skeleton, resulting in microcracks in some weak bonding positions of clay particles. In addition, cementation substances in the soil may also be dissolved or softened, and the softened cementation substances and water film play lubricating roles in the soil, leading to a reduction in the friction resistance between clayey clay particles. These will destroy the bonding between soil structures and allow the sliding between clay particles. On the osmotic swelling stage, the smectite lattice spacing of the soils may increase due to the hydration. It results in the soils further dispersing into fine particles. Each fine particle could further absorb water molecules and hydration cations to form thicker hydrate films. Furthermore, the diffusion of the double layer repulsion should cause a lattice layer separation to seriously disperse into very thin sheets, resulting in a significant decrease in strength.

During the process of repeated wet and dry cycles, the occurrence of a large number of macro- and microcracks, which gradually decreases from the surface of the slope to the interior of the active zone in-situ, destroys the integrity, identity, and continuity of the soil mass. Alternatively, the continuous accumulation of the plastic strain will cause losses in cohesion of shear strength resulting from the bonding of clay particles. The cementation effect caused by the iron and manganese oxides existing in the natural samples may be destroyed, resulting in a loose structure. In addition, the natural original structure or the bonding of the soil might be irreversibly broken down by wet-dry cycles [30], especially for the soils in the surficial layer of the slope.

Therefore, it should be noted that the expansive soil has a remarkable swelling characteristic being different from the common soils, the shear strength of which should account for the effect of wet and dry cycles as well as the effect of overburden pressures. Surface soil in shallower expansive soil slopes has more severe attenuation of shear strength.

\section{Surficial Stability Analysis of Expansive Soil Cutting Slope}

3.1. Effect of Routine Shear Strength Parameter on Expansive Soil Cutting Slope Stability. To investigate the effect of shear strength parameters on the expansive soil slope stability, a series of limit equilibrium analyses were carried out using Slope/W [31]. It is well known that the surface expansive soil with loose structures, and a large number of micro- and macrofissures due to wet-dry cycles, can be close to or approaching fully saturation condition during or after a long-term rainfall. This highly unfavorable condition should be considered to analyze the slope stability in general. Therefore, it was taken into account in this study.

A homogeneous slope was assumed for this limit equilibrium analysis with a height of $6.0 \mathrm{~m}$ and a slope ratio of $1: 1.5(\mathrm{~V}: \mathrm{H})$. The side and bottom boundaries were no flow boundaries. The others were flux boundaries to model the infiltration phases of rainfall, and constant water pressure was prescribed to simulate the field situations 
TABLe 3: Physical and mechanical properties of expansive soil.

\begin{tabular}{ccccc}
\hline & Unit weight $(\mathrm{kN})$ & Saturated permeability coefficient $(\mathrm{m} / \mathrm{s})$ & Effective friction angle $\left(^{\circ}\right)$ & Effective cohesion $(\mathrm{kPa})$ \\
\hline Soil properties & 20 & $2.3 e^{-7}$ & $9,12,15,18,21,24$ & $0,1,2,3,5,7.5,10,15,20,25,30$ \\
\hline
\end{tabular}

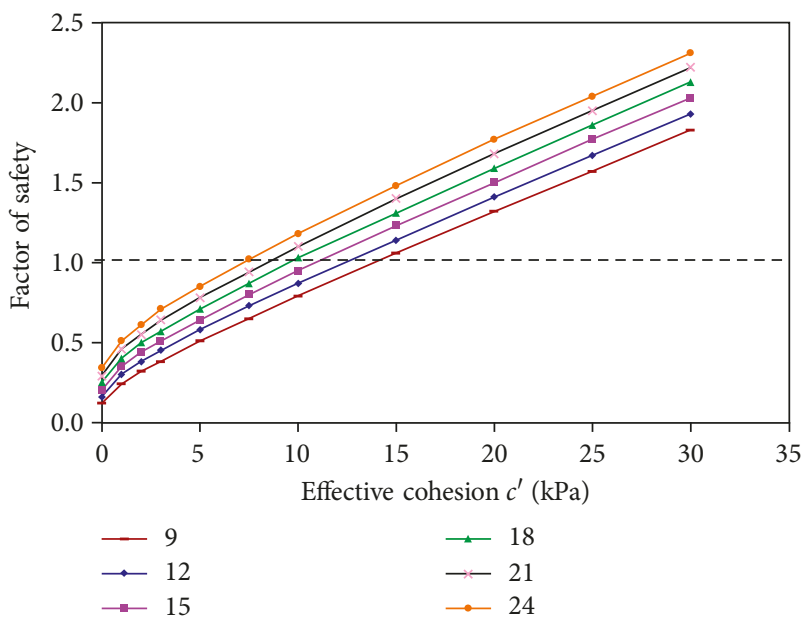

FIgURE 6: Relationship between factor of safety and effective cohesion $c^{\prime}$.

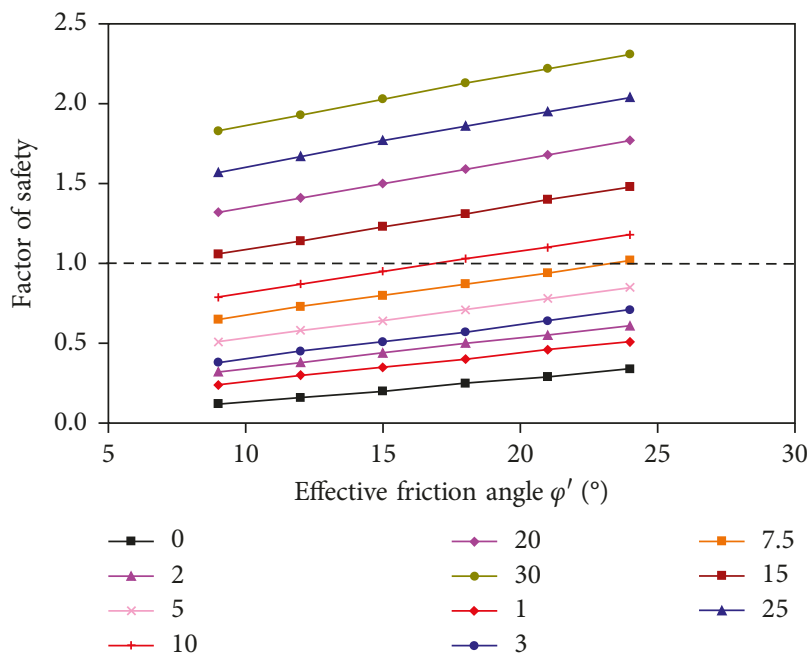

FIgURE 7: Relationship between factor of safety and effective friction angle $\varphi^{\prime}$.

(i.e., runoff). It should be noted that the slope was not prescribed by layers with different saturated permeability coefficients according to the effect of wet-dry cycles, because the fully saturation condition was focused on in this study. The initial ground water table was horizontal at the elevation of $1.0 \mathrm{~m}$. A saturated steady seepage flow state calculated is shown in Figure 5. The physical and mechanical properties of expansive soil assumed in the different analyses are indicated in Table 3.

Figures 6 and 7 show the factors of safety, calculated using the simplified Bishop method with different effective cohesions and effective friction angles, respectively. The dashed line for the factor of safety of 1.0 gives the range of

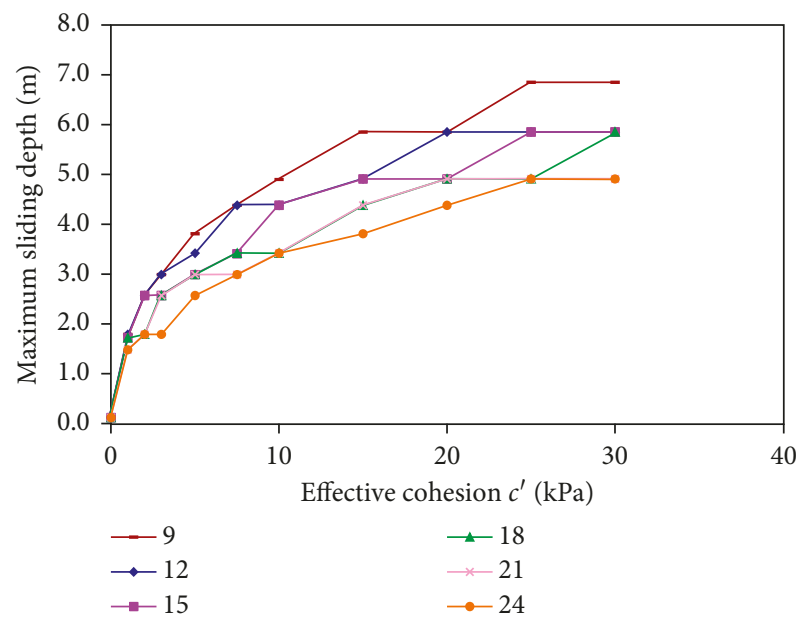

FIGURE 8: Relationship between the maximum sliding vertical depth and effective cohesion $c^{\prime}$.

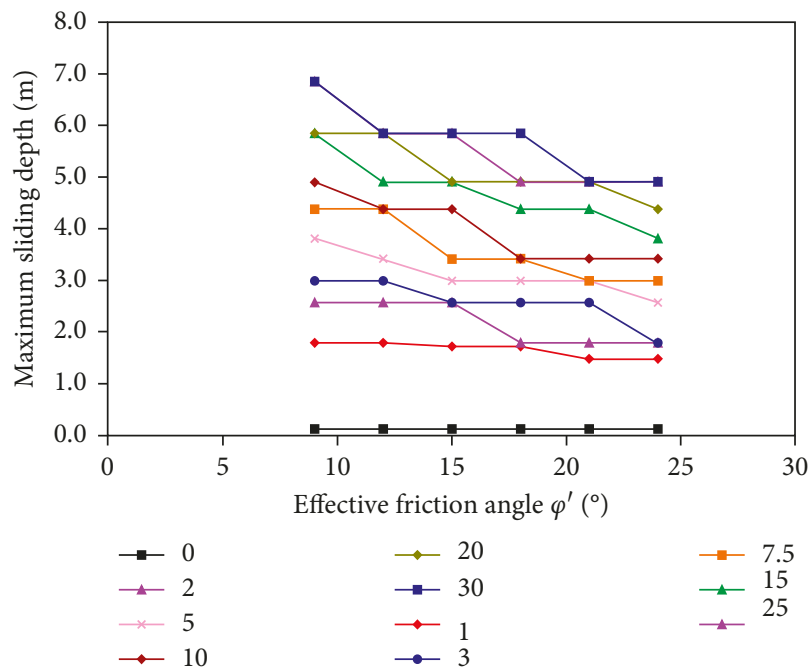

Figure 9: Relationship between the maximum sliding vertical depth and effective friction angle $\varphi^{\prime}$.

shear strength parameters for the slope in the limit equilibrium state. For the saturated steady seepage state, the factor of safety increases nonlinearly with effective cohesions less than $5 \mathrm{kPa}$ for a given effective friction angle, and then increases linearly nearly. On the contrary, the factor of safety increases linearly with increasing effective friction angle for a given effective cohesion.

In the limit equilibrium state, the effective cohesion and the effective friction angle obtained, respectively, are approximately $\left(7.0 \mathrm{kPa}, 24^{\circ}\right),\left(8.2 \mathrm{kPa}, 21^{\circ}\right),\left(9.3 \mathrm{kPa}, 18^{\circ}\right)$, $\left(10.6 \mathrm{kPa}, 15^{\circ}\right),\left(12.2 \mathrm{kPa}, 12^{\circ}\right)$, and $\left(13.8 \mathrm{kPa}, 9^{\circ}\right)$. The factor of safety increases from 0.34 to 1.48 with the effective cohesion changing from 0 to $15 \mathrm{kPa}$ for the effective friction angle of 
$24^{\circ}$. However, the factor of safety only increases from 0.79 to 1.18 , as the effective friction angle increases from $9^{\circ}$ to $24^{\circ}$, respectively, for the effective cohesion of $10 \mathrm{kPa}$. These findings indicate that the variations in the effective cohesion have a greater impact on the factor of safety than changes in the effective friction angle. When the effective cohesion exceeds $15 \mathrm{kPa}$, the factor of safety is greater than 1.0 .

Figures 8 and 9 show the maximum sliding vertical depth for different effective cohesions and effective friction angles, respectively. From Figures 8 and 9, it can be seen that the maximum sliding vertical depth increases sharply from $0.12 \mathrm{~m}$ to more than $1.48 \mathrm{~m}$ when the effective cohesion varied from $0 \mathrm{kPa}$ to $1 \mathrm{kPa}$ for the effective friction angle in the range of $9^{\circ}$ and $24^{\circ}$. Furthermore, when the maximum sliding vertical depths are $2.0 \mathrm{~m}$ and $3.0 \mathrm{~m}$, the corresponding effective cohesions are less than $4 \mathrm{kPa}$ and $7.5 \mathrm{kPa}$, respectively. This indicates that the maximum sliding vertical depth increases considerably with increasing effective cohesion for a given effective friction angle. The effect of effective friction on the maximum sliding vertical depth increases with increasing the effective cohesion (as seen in Figure 9). However, the variations in the maximum sliding vertical depth with increasing the effective friction are not remarkable than that with increasing the effective cohesion. Therefore, the effective cohesion which is small is a vital factor to the occurrence of the surficial failure of the expansion soil slope. Day [32] also proposed that the factor of safety for the surficial stability is highly dependent on the effective cohesion.

\subsection{Effect of Nonlinear Shear Strength Parameter on Expansive} Soil Cutting Slope Stability. There is a built-in universal datapoint strength function in Slope/W to describe the nonlinear shear strength envelope of the materials (soils or rocks) in a stability analysis, using the limit equilibrium method. For each slice, Slope/W first computes the effective normal stress at the slice base and then calculates the slope (tangent) of the nonlinear curve at the slice base effective normal stress as to be $\varphi^{\prime}$ for that slice. The tangent is projected to the origin axis to compute an intercept as to be $c^{\prime}$. Consequently, each slice has a $c^{\prime}$ and $\varphi^{\prime}$, corresponding to the slice base effective normal stress (as seen in Figure 10).

Based on the same slope calculation model and boundary conditions as seen in Figure 5, the measured nonlinear shear strength data of no wet-dry cycles with loading, and eight wet-dry cycles with loading, were introduced in Slope/W. The factor of safety calculated and the maximum sliding depth obtained are shown in Figures 11 and 12 , respectively.

The factor of safety calculated using the nonlinear shear strength of a natural expansive soil cutting slope without wet-dry cycles is 2.32 , and the maximum vertical sliding depth is $4.38 \mathrm{~m}$. The results clearly indicate that the newly excavated expansive soil slope without original structural fissures is stable even in a full saturation condition. However, the factor of safety reduces considerably to 0.94 when the expansive soils are subjected to eight wet-dry cycles with loading, and the maximum vertical sliding depth is only

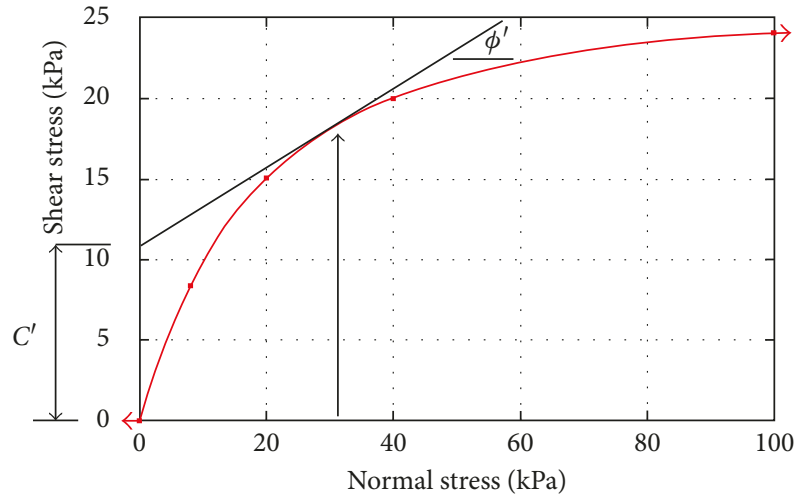

FIGURE 10: General data-point shear-normal function.

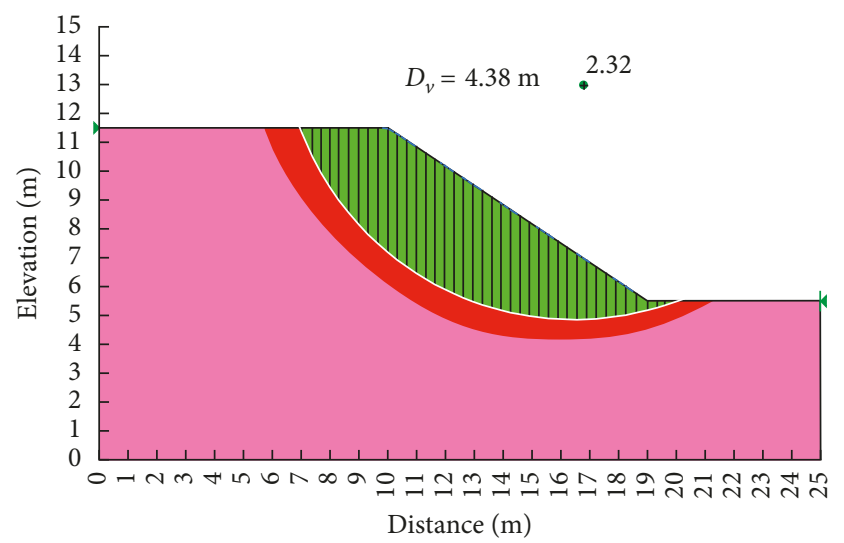

FIgURE 11: Factor of safety and the maximum vertical sliding depth (no wet-dry cycles with loading).

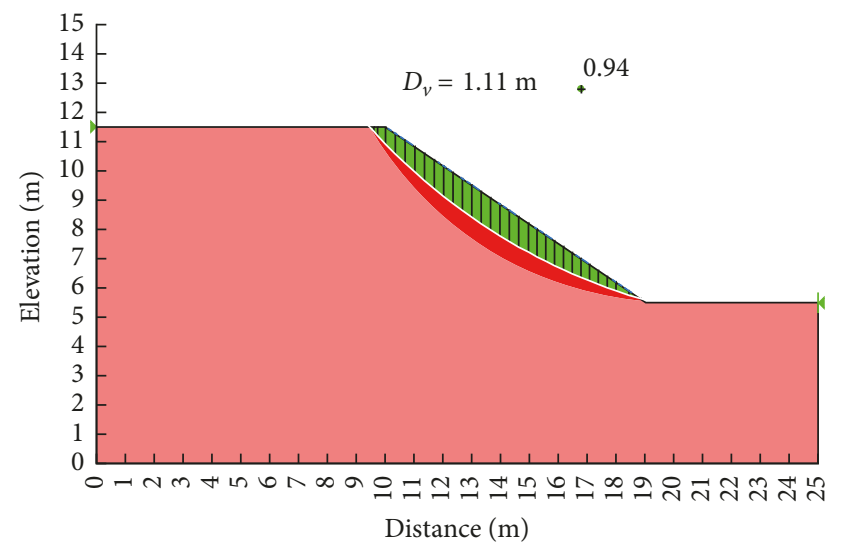

FIGURE 12: Factor of safety and the maximum vertical sliding depth (after eight wet-dry cycles with loading).

$1.11 \mathrm{~m}$. This result is fundamentally in agreement with the results observed in-situ [1]. It illustrates that a surficial failure of the expansive soil slope will occur when it is close to the saturation condition, during or after long-term continuous rainfall, due to the shear strength of surface soils of slope continuously decreasing after subjected to the repeated wet-dry cycles. 


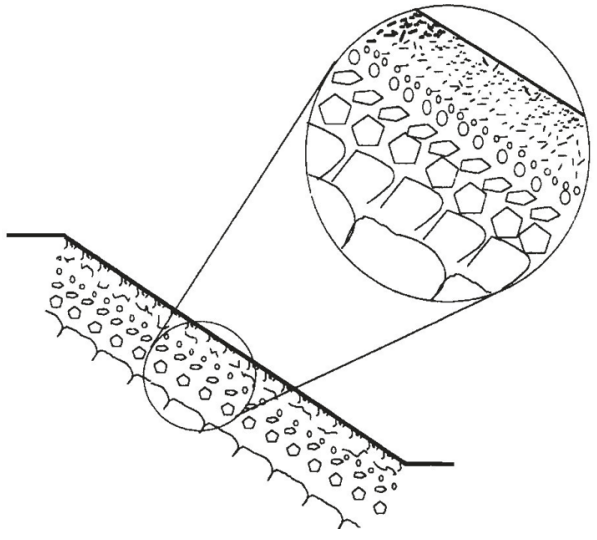

Figure 13: Slaking of expansive clay soil due to swelling [36].

3.3. Discussion on Surficial Failure of Expansive Soil Cutting Slope. The previous research has shown that the strength reduces due to swelling of expansive soils after absorbing water, and this potential is controlled by the overburden pressure. Therefore, to a large extent, the shear strength relates to the overburden pressure. Studies of dams filled with expansion soils have indicated that the shear strength parameters should be different due to gravity stress variation in different depths [33]; research also shows that the expansive soil in the middle of the dam, which was subjected to $200 \mathrm{kPa}$ pressure, can also maintain a high shear strength $\left(c^{\prime}=80 \mathrm{kPa}, \varphi^{\prime}=11^{\circ}\right)$, but the strength is almost close to zero near the surface of slope in the absence of effective protections. Therefore, the shear strength parameter of expansive soil selected to analyze the slope stability should vary according to different locations. Otherwise, it will result in a wrong analysis result for a surficial failure of expansive soil cutting slopes. For the surficial failure of expansive soil slopes, the back-calculated effective cohesion ranges mostly between 2 and $4 \mathrm{kPa}$. This is far less than the traditional shear test results [33] and is basically in agreement with the nonlinear shear strength parameters, considering the combined effects of the wet-dry cycle and low normal stress.

Generally, a newly excavated expansive soil slope that is free of wet-dry cycles is stable because there are no shrinkage cracks except for only a small number of unloading cracks or fissures; hence, the strength of more intact slope soil does not attenuate even if the saturated shear strength is also high. Moreover, the permeability coefficient of the surface soil is very small, and it can be considered impermeable. Therefore, the influence of rainfall on the surface soil is very limited, and it is still not saturated, leading to a stable slope. When treatment measures are not timely or invalid, numerous macroand microshrinkage cracks will occur on the slope surface soil after the wet-dry cycles, undermining the integrity of the slope (as seen in Figure 13). This will lead to the development of an extensive network of cracks and fissures, which provides a convenient channel for the rainfall readily infiltrating into the surface slope and increases the permeability of surface regolith soil. Then, the near surface soil will be more permeable than the deeper soil. It will lead to the deeper soil being less weathered, and thus the intact expansive soil or claystone has a lower permeability $[29,34]$. As the number of wet and dry cycles increase, the affected depth will increase continuously until it reaches a stable depth. During the wet-dry cycle, the shear strength of the surface soil continues to attenuate. There is a greater decrease in strength near the slope surface, even being close to or approaching zero. This process will vary and depends on the weather and other environmental conditions. Therefore, the failure time can vary from several months to several years [35]. This finding reveals why an expansive soil slope is usually stable during excavation or after excavation for a short time.

Therefore, there might be three important factors resulting in a surficial failure of an expansive soil slope: remarkable degreasing shear strength of surface soil subjected to wet-dry cycles, increasing permeability coefficient of surface soil, and continuous or heavy rainfall after a long drought.

\section{Flexible Support Treatment Measure for Expansive Soil Cutting Slope}

4.1. Design and Construction of Geogrid Reinforced Flexible Support Structure. For a project, the technical measures used to treat expansive soil cutting slopes can be categorized as rigid and flexible treatment techniques. Common rigid treatment structures include a self-weight retaining wall, antislide piles, or a schistous slope wall. For these structures, the shear fracture or extrusion failure often occurs due to the swelling deformation of expansive soil slopes after wetting. It will result in a large swelling force exceeding the resistance of the rigid structure. Therefore, according to the characteristics of the surficial failure of expansive soil cutting slopes, flexible techniques using geotextiles, are more suitable for cutting slopes in expansive soil areas. This is because that a flexible structure allows a limited deformation of the slope surface and can adsorb the energy produced by the swelling and horizontal slope deformation. And then, a new balance for an expansive soil cutting slope will be reached.

A typical design diagram of the expansive soil cutting slope treated by the geogrid reinforced flexible support structures is shown in Figure 14.

The construction of the geogrid reinforced flexible structure can be described as follows [37, 38]:

(1) The designed cutting slope is overexcavated to a designed width, which depends on the depth obviously affected by the atmosphere and exceeds $3.5 \mathrm{~m}$ in general.

(2) The geogrid is placed, and the fill layer is then backfilled and compacted, layer by layer with a thickness of $50 \mathrm{~cm}$ for each layer.

(3) The layer with the geogrid is back-enveloped with a $1 \mathrm{~m}$ lap length, and the next geogrid is placed on the layer. 


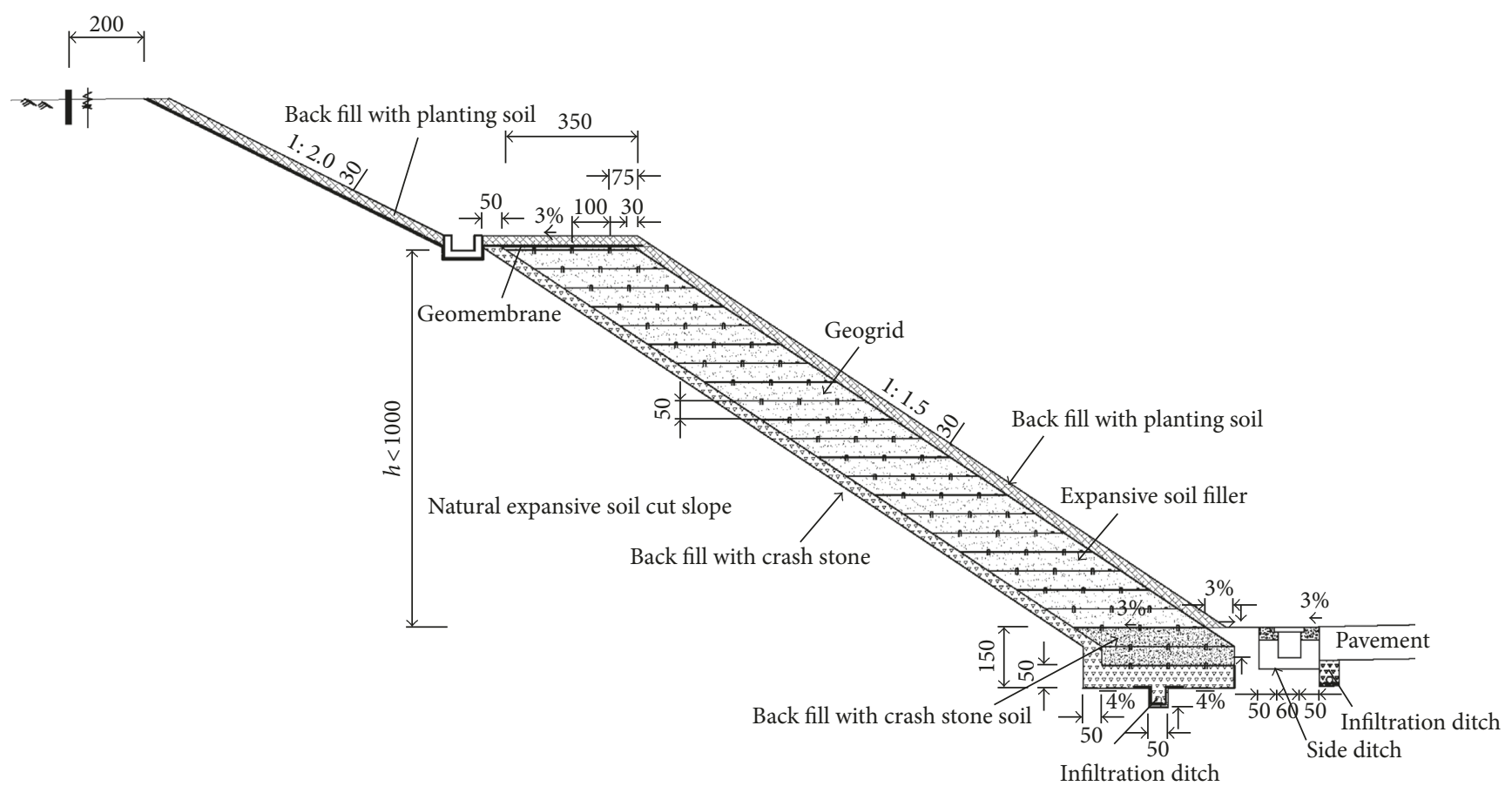

FIGURE 14: A typical design diagram of geogrid reinforced flexible support structure (unit: centimeter).

(4) The upper and lower geogrid layers are connected with connecting rods, and then the fill is backfilled and compacted with a new layer.

(5) Steps 3 and 4 are repeated to the designed height, and the slope of the geogrid reinforced structure is adjusted to $1: 1.5(\mathrm{~V}: \mathrm{H})$.

(6) During the process of construction, drainage facilities are constructed in the back and the subbase of the geogrid reinforced structure.

(7) When the geogrid reinforced structure is completed, a moisture barrier is constructed at the top of the slope.

The working mechanism of the geogrid reinforced flexible structure can be summarized as follows:

(1) The friction and interlocking between the geogrid and the filler, along with the enveloping and connecting of the layers of the geogrid, can reinforce the layers as a whole to stabilize the reinforced structure.

(2) The swelling stress in the slope will be released through the deformation of the slope surface, which is permitted to a certain degree. Moreover, the large dead weight of the structure is beneficial to restrain the deformation [12].

(3) The structure covering the face of a freshly cutting slope has a slope of $1: 1.5$ and a thickness exceeding $3.5 \mathrm{~m}$, which prevents or considerably reduces the attenuation of shear strength due to the noticeable decrease in the effect of weathering (i.e., the wet-dry cycles). At the same time, the self-weight of the reinforced structure can increase the strength of the slope soil as discussed above.

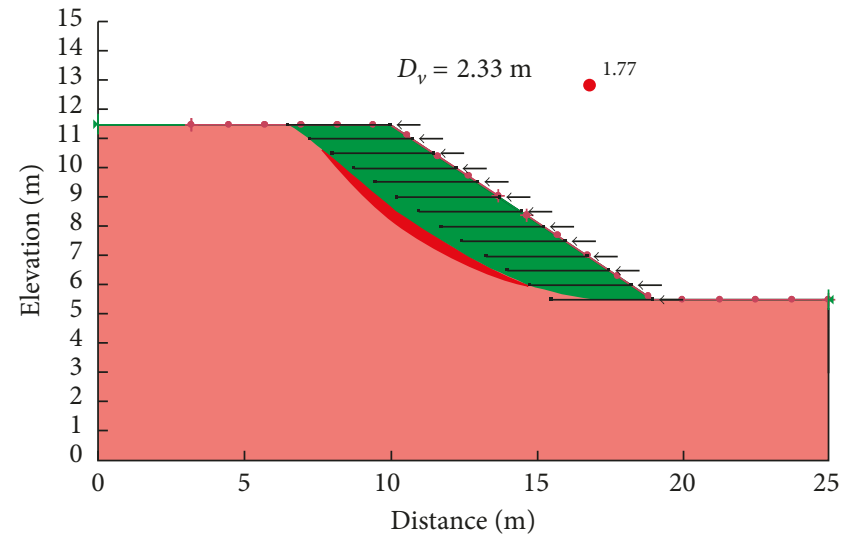

FIGURE 15: Factor of safety of geogrid reinforced slope.

4.2. Stability Analysis of Expansive Soil Cutting Slope Treated by Geogrid Reinforced Flexible Structure. The comparison of factor of safety of expansive soil cutting slope treated by geogrid reinforced flexible structure or not are only focused in this paper. The slope calculation model and boundary conditions are assumed as the same as seen in Figure 5. The measured nonlinear shear strength data of eight wet-dry cycles with loading were introduced in Slope/W. The geogrid reinforced spacing and length were $0.5 \mathrm{~m}$ and $3.5 \mathrm{~m}$, respectively. The interface apparent cohesion and apparent friction between geogrid and expansive soil were $8.1 \mathrm{kPa}$ and $6.9^{\circ}[39]$, respectively. The geogrid layouts and the calculated factor of safety of slope treated by the geogrid reinforced flexible structure are shown in Figure 15. 


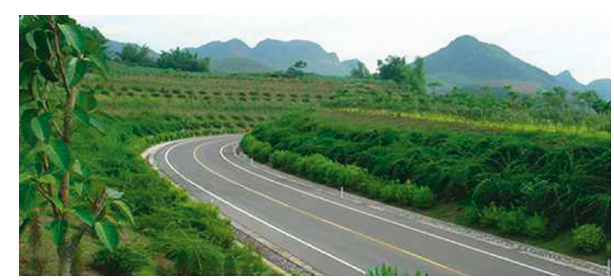

(a)

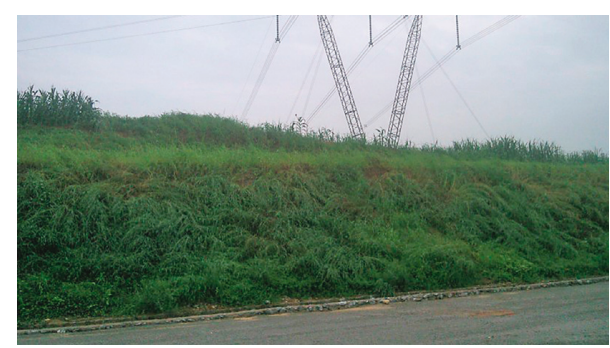

(b)

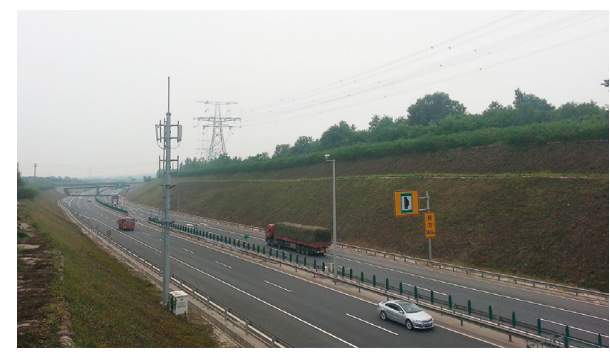

(c)

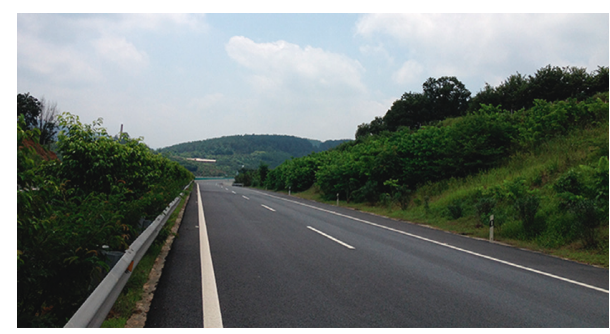

(d)

FIGURE 16: Photos of expansive soil cut slope treated by geogrid reinforced flexible support measures. (a) Nanning to Youyi Guan expressway (a ramp slope $350 \mathrm{~m}$ long and $20 \mathrm{~m}$ high). (b) Baise to Longlin expressway (a slope $160 \mathrm{~m}$ long and $8.7 \mathrm{~m}$ high). (c) Beijing west sixth ring expressway (a slope $1.2 \mathrm{~km}$ long and $22.3 \mathrm{~m}$ high). (d) Nanning outer ring expressway (a slope $246 \mathrm{~m}$ long and $9.2 \mathrm{~m}$ high).

From Figure 15, it can be seen that the position of the most dangerous sliding surface was moved from shallow (1.11 m vertical depth as seen in Figure 12) to the rear of the geogrid (about $2.33 \mathrm{~m}$ vertical depth). The safety factor of slope treated by the geogrid reinforced flexible structure was 1.77. It is much greater than safety factor of 0.94 for natural slope as seen in Figure 12. Therefore, the effect of the geogrid reinforced flexible structure on the stability of expansive slopes is significant. It can notably improve the stability of slope.
4.3. Application of Geogrid Reinforced Flexible Structure to Treat Cutting Slopes in Practice. According to the working mechanism for the flexible structure to treat cutting slopes mentioned above, fourteen expansive soil failure cutting slopes located in Nanning to Youyi Guan expressway were treated using the geogrid reinforced flexible support in 2003, which are stable till now after about fourteen years of seasonal wet-dry cycles and several typhoon rainstorms (Figure 16(a)). It also can be seen from Figure 16(a) that the treated expansive soil cutting slope is environment friendly. After that, this technique was applied to treat six expansive soil cutting slopes from Baise to Longlin expressway from 2008 to 2009 (Figure 16(b)), cutting slopes of $1.2 \mathrm{~km}(\mathrm{~K} 9+600 \sim \mathrm{K} 10+800)$ of Beijing west sixth ring expressway in 2010 (Figure 16(c)), and eighteen expansive soil cutting slopes of the Nanning outer ring expressway from 2010 to 2012 (Figure 16(d)). All these cutting slopes are still in good operational condition and environment friendly.

\section{Conclusions}

Based on the laboratory tests on natural Nanning expansive soil, the stability of expansive soil cutting slope was analyzed and the application of flexible support treatment measure was described, and the following conclusions can be drawn:

(1) The shear strength envelope of natural Nanning expansive soil subjected to repeated wet-dry cycles with loading is nonlinear and can be well fitted by a generalized power function. The occurrence of the surficial failure of expansive soil cutting slopes is very different from general clays. This is because the shear strength of the expansive soil decreases significantly due to the effect of wet-dry cycles. This decrease in the effective cohesion especially is considerable, and it can even be close to or equals zero.

(2) When analyzing the stability of expansive soil cutting slopes, the selection of shear strength parameters must consider the combined effects of wet-dry cycles and low stress. The results of slope stability, achieved using nonlinear shear strength parameters, are basically consistent with the actual conditions, indicating that the method is reasonable and reliable. The application of practical engineering methods for treatment expansive soil cutting slopes proves that the geogrid flexible support treatment measure is effective and environment friendly.

\section{Conflicts of Interest}

The authors declare that they have no conflicts of interest.

\section{Acknowledgments}

This work was supported by the National Key Research and Development Program of China (2017YFC0805300), the National Natural Science Foundation of China (51478054 
and 51608053), Natural Science Foundation of Hunan Province (2017JJ3335), Key Project of Education Department of Hunan Province (17A008), Open Fund of State Engineering Laboratory of Highway Maintenance Technology (Changsha University of Science \& Technology) (kfj150103), Open Fund of Engineering Research Center of Catastrophic Prophylaxis and Treatment of Road \& Traffic Safety of Ministry of Education (Changsha University of Science \& Technology) (kfj20160401), Jiangxi Communications Department Program (2013C0011), and the Scientific Research Fund of Hunan Provincial Education Department (15C0043).

\section{References}

[1] S. W. Liao, Expansive Soil and Railway Engineering, China Railway Publishing House, Beijing, China, 1984.

[2] D. K. McCook, "Discussion of modeling for analyses of fully softened levees," in Proceedings of the 32nd Annual USSD Conference, Innovative Dam and Levee Design and Construction for Sustainable Water Management, New Orleans, LA, USA, April 2012.

[3] W. S. Wang, Y. L. Xie, and J. L. Liang, "Classification of expansive clay slope on road cutting," Journal of Chang'an University, vol. 25, no. 1, pp. 20-24, 2005.

[4] Z. Wang, B. W. Gong, and C. G. Bao, "Measurement of matrix suction of expansive soil slope in Northern Hubei," Chinese Journal of Geotechnical Engineering, vol. 23, no. 1, pp. 64-67, 2001.

[5] M. Dinesh and S. Chandra, "Frictional resistance of bored piles in expansive clays," Géotechnique, vol. 11, no. 4, pp. 294-301, 1961.

[6] D. A. Sun, W. J. Sun, and L. Xiang, "Effect of degree of saturation on mechanical behaviour of unsaturated soils and its elastoplastic simulation," Computers and Geotechnics, vol. 37, no. 5, pp. 678-688, 2010.

[7] T. Elkady and M. Abbas, "Shear strength behavior of highly expansive soil," in Proceedings of the GeoCongress 2012, pp. 2532-2541, Oakland, CA, USA, March 2012.

[8] M. M. Sherif, O. Mazen, and N. S. Gergis, "Behaviour of expansive soil during shear," in Proceedings of the First $\mathrm{Na}$ tional Conference on the Science and Technology of Buildings, pp. 557-562, Khartoum, Sudan, 1984.

[9] A. A. Darrag, Effect of Swelling on the Shear Strength of Egyptian Expansive Soils, M.Sc. thesis, Cairo University, Cairo, Egypt, 1984.

[10] A. I. Al-Mhaidib and M. A. Al-Shamrani, "Influence of swell on shear strength of expansive soils," in Proceedings of the GeoShanghai Conference Advances in Unsaturated Soils, Seepage, and Environmental Geotechnics, vol. 148, pp. 160165, Geotechnical Special Publication, 2006.

[11] R. C. K. Wong, "Swelling and softening behaviour of La Biche shale," Canadian Geotechnical Journal, vol. 35, no. 2, pp. 206-221, 1998.

[12] R. Zhang, H. P. Yang, and J. L. Zheng, "The effect of vertical pressure on the deformation and strength of expansive soil during cyclic wetting and drying," in Proceedings of the Unsaturated Soils, 2006, pp. 894-905, Carefree, AZ, USA, April 2006.

[13] B. N. Shanker and S. Krishna, "Laboratory studies on shear strength of expansive clays," in Proceedings of Indian Geotechnical Conference, vol. 1, pp. 155-158, Vishakhaptnam, India, December 1989.

[14] B. N. Shanker, V. Saikrishna, and G. N. Reddy, "Effect of drainage conditions on shear strength of swollen expansive soils," in Proceedings of the Indian Geotechnical Conference, pp. 247-249, Bombay, India, December 1990.

[15] R. K. Katti, D. R. Katti, and A. R. Katti, Behaviour of Saturated Expansive Soils and Control Methods, A. A. Balkema, Rotterdam, Netherlands, 2002.

[16] H. P. Yang, J. Xiao, S. Wang, and W. R. Zuo, "Study on the determination of residual shear strength for expansive soil," in Proceedings of the Recent Advancement in Soil Behavior, in Situ Test Methods, Pile Foundations, and Tunneling, vol. 192, pp. 49-54, Geotechnical Special Publication, Changsha, Hunan, China, August 2009.

[17] B. Tiwari, T. L. Brandon, H. Marui, and G. R. Tuladhar, "Comparison of residual shear strengths from back analysis and ring shear tests on undisturbed and remolded specimens," Journal of Geotechnical and Geoenvironmental Engineering, vol. 131, no. 9, pp. 1071-1079, 2014.

[18] J. H. Zhang, Q. P. Jiang, Y. Q. Zhang, L. L. Dai, and H. X. Wu, "Nondestructive measurement of water content and moisture migration of unsaturated red clays in South China," Advances in Materials Science and Engineering, vol. 2015, Article ID 542538, 7 pages, 2015.

[19] ASTM Standard Test Method D 4220, Standard Practices for Preserving and Transporting Soil Samples, Annual Book of ASTM Standards, ASTM International, vol. 04.08, West Conshohocken, PA, USA, 2000.

[20] ASTM Standard Test Method D 3080, Standard Test Method for Direct Shear Test of Soils under Consolidated Drained Conditions, vol. 04.08, Annual Book of ASTM Standards, ASTM International, West Conshohocken, PA, USA, 2000.

[21] L. T. Zhan and C. W. W. Ng, "Shear strength characteristics of an unsaturated expansive clay," Canadian Geotechnical Journal, vol. 43, pp. 751-763, 2006.

[22] G. Lefebvre, "Strength and slope stability in Canadian soft clay deposits," Canadian Geotechnical Journal, vol. 18, no. 3, pp. 420-442, 1981.

[23] B. B. F. De Mello, "Reflections on design decisions of practical significance to embankment dams-17th Rankine Lecture," Géotechnique, vol. 27, no. 3, pp. 281-354, 1977.

[24] J. A. Charles and K. S. Watts, "The influence of confining pressure on the shear strength of compacted rockfill," Géotechnique, vol. 30, no. 4, pp. 353-367, 1980.

[25] M. Maksimovic, "Nonlinear failure envelope for soils," Journal of Geotechnical Engineering, vol. 115, no. 4, pp. 581-586, 1989.

[26] J. Perry, "A technique for defining non-linear shear strength envelopes and their incorporation in a slope stability method of analysis," Quarterly Journal of Engineering Geology and Hydrogeology, vol. 27, no. 3, pp. 231-241, 1994.

[27] P. V. Lade, "The mechanics of surficial failure in soil slopes," Engineering Geology, vol. 114, pp. 57-64, 2010.

[28] R. Baker, "Nonlinear Mohr envelopes based on triaxial data," Journal of Geotechnical and Geoenvironmental Engineering, vol. 130, pp. 498-506, 2004.

[29] R. W. Day, "Discussion on slope failures in Tertiary expansive OC clays," Journal of Geotechnical and Geoenvironmental Engineering, vol. 125, pp. 427-431, 1999.

[30] L. T. Zhan, R. Chen, and C. W. W. Ng, "Wetting-induced softening behavior of an unsaturated expansive clay," Landslides, vol. 11, pp. 1051-1061, 2014.

[31] Geo-Slope International Ltd., Stability Modeling with Slope/W 2007 Version, an Engineering Methodology, Calgary, AB, Canada, 3rd edition, 2008. 
[32] R. W. Day, "Surficial stability of compacted clay: case study," Journal of Geotechnical Engineering, vol. 120, no. 11, pp. 1980-1990, 1994.

[33] T. H. Liu, Problems Related to Expansive Soil in Engineering Constructions, China Architecture and Building Press, Beijing, China, 1997.

[34] A. E. Templeton, G. L. Sills, and L. A. Cooley, "Long term failure in compacted clay slopes," in Proceedings International Conference on Case Histories in Geotechnical Engineering, vol. 2, pp. 749-754, University of Missouri at Rolla, St. Louis, MO, USA, June 1993.

[35] Z. J. Zhang, M. J. Tao, and M. Morvant, "Cohesive slope surface failure and evaluation," Journal Geotechnical and Geoenvironmental Engineering, vol. 131, no. 7, pp. 898-906, 2005.

[36] J. A. R. Ortigao, T. R. R. Loures, C. Nogueira, and L. S. Alves, "Slope failures in Tertiary expansive OC clays," Journal of Geotechnical and Geoenvironmental Engineering, vol. 123, pp. 812-817, 1997.

[37] H. P. Yang, J. L. Zheng, and R. Zhang, "Addressing expansive soils," Civil Engineering, vol. 77, no. 3, pp. 62-69, 2007.

[38] J. L. Zheng, R. Zhang, and H. P. Yang, "Highway subgrade construction in expansive soil areas," Journal of Materials in Civil Engineering, vol. 21, no. 4, pp. 154-162, 2009.

[39] H. P. Yang, L. Wan, and J. L. Zheng, "Development and application of large scale numerical control pullout test system," Chinese Journal of Geotechnical Engineering, vol. 29, no. 7, pp. 1080-1084, 2007. 


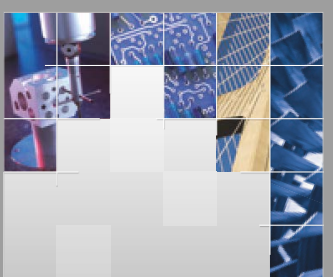

\section{Enfincering}
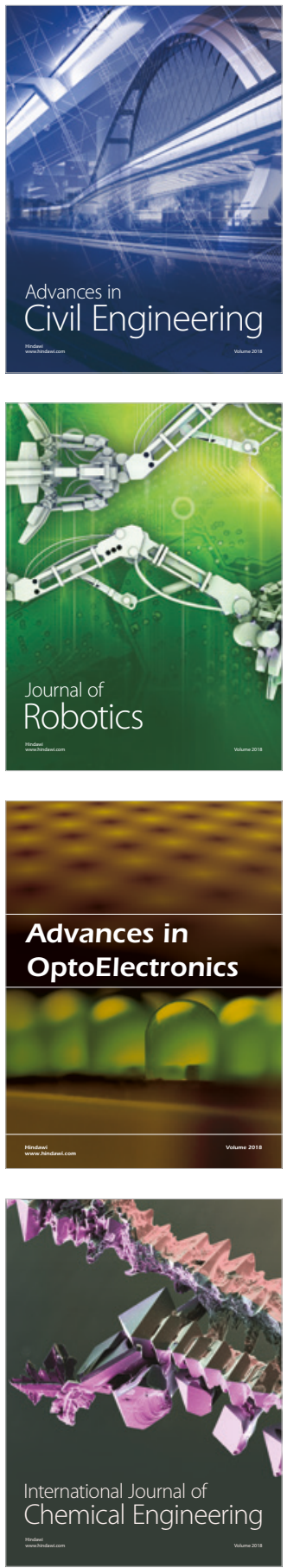

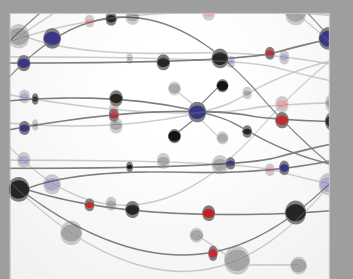

\section{Rotating \\ Machinery}

The Scientific World Journal

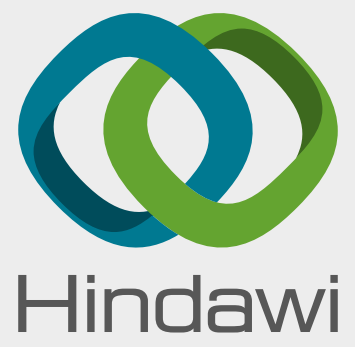

Submit your manuscripts at

www.hindawi.com
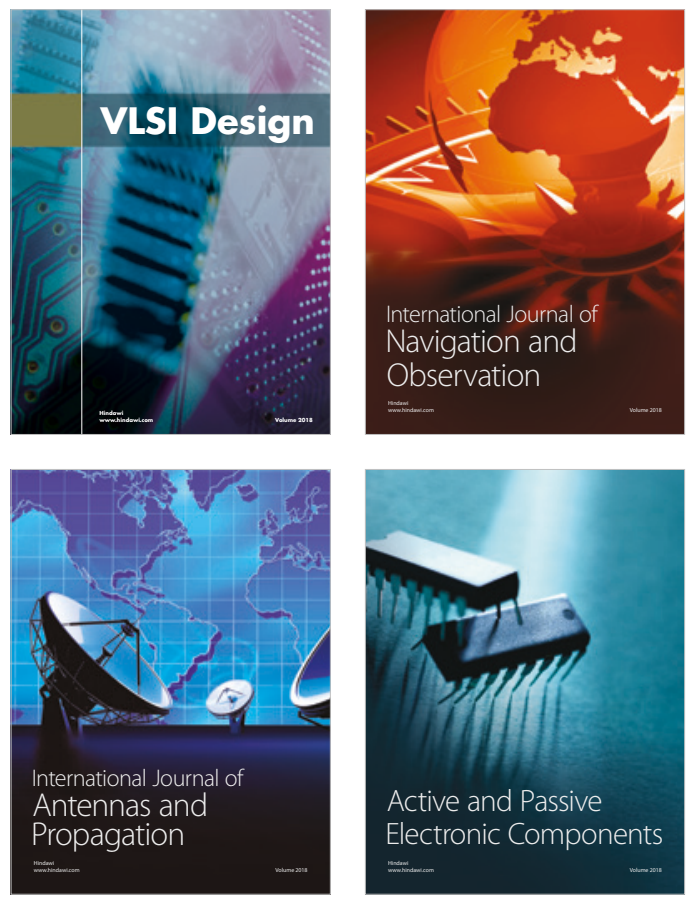
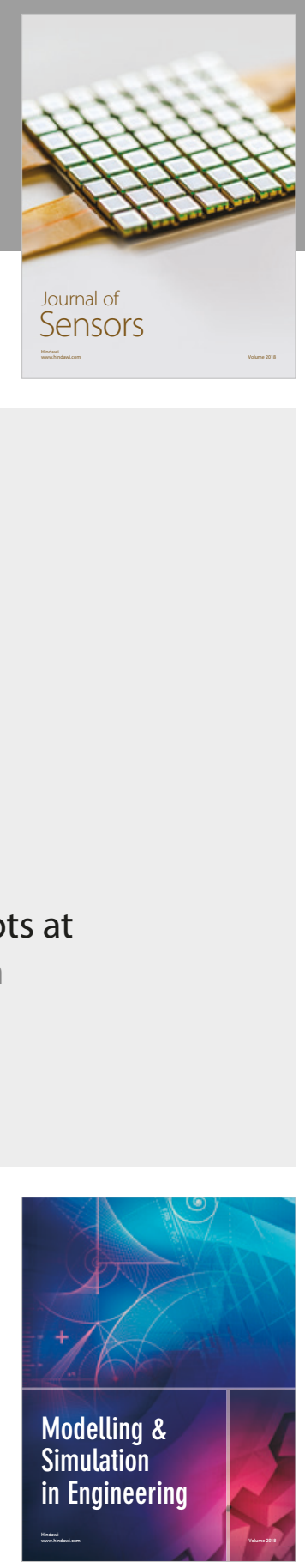

\section{Advances \\ Multimedia}
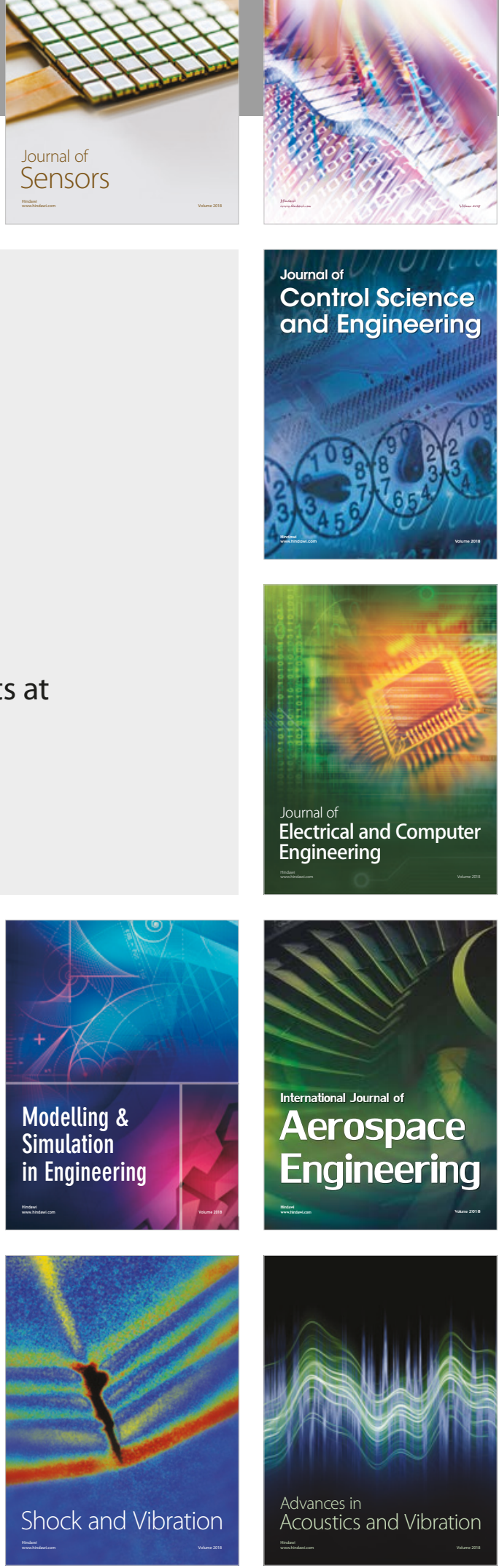